\title{
Bioactive Betulin produced by marine Paecilomyces WE3-F
}

\author{
Khouloud Barakat*, Mohamed Saleh \\ Marine Microbiology Laboratory, Division of Marine Environment, National Institute of Oceanography and Fisheries, Alexandria, Egypt.
}

\begin{tabular}{l} 
ARTICLE INFO \\
\hline Article history: \\
Received on: $30 / 12 / 2015$ \\
Revised on: $17 / 01 / 2016$ \\
Accepted on: $31 / 01 / 2016$ \\
Available online: $30 / 03 / 2016$ \\
\hline Key words: \\
Marine Paecilomyces, \\
antibacterial activity, Placket \\
Burman design, chemical \\
analysis, betulin.
\end{tabular}

\begin{abstract}
Objective: Marine fungi play an important role in human and animal health, leading compounds to new drug discoveries and prospects for their bioactivity potential.

Materials and Methods: Paecilomyces WE3-F was isolated from marine sediment (Red Sea, Shalateen, Egypt). Fungal isolate was screened for their antagonistic activity against four Gram-positive (Bacillus cereus, Lesteria monocytogenes, Micrococcus luteus and Staphylococcu aureus) and four Gram-negative (Aeromonas hydrophila, Flavobacteruim sp, Pseudomonas aeruginosa and Vibrio cholera,) pathogenic bacteria. Paecilomyces WE3-F was identified using $18 \mathrm{~S}$ rRNA technology. Seven factors were chosen to be screened for bioactivity using the Placket Burman experimental design: sucrose, yeast extract, $\mathrm{Na} \mathrm{NO}_{3}$, temperature, initial $\mathrm{pH}$, inoculum size, and incubation period.

Results: Among conditional factors, acidic $\mathrm{pH}$ and $1.5 \mathrm{ml}$ inoculum size favored the bioactive metabolites. Furthermore, a number of solvents have been experimented for the extraction of the bioactive metabolite(s). Dichloromethane (DCM) crude extract from the fermentation broth of a marine Paecilomyces WE3-F showed the highest activity with averages of 26 and $24 \mathrm{~mm}$ against G-ve and G+ve, respectively. Under optimal culture conditions, the maximum extractable compound concentration in a $10-\mathrm{L}$ culture medium reached $83.4 \mathrm{mg} / \mathrm{L}$. Based on data obtained by thin layer chromatogram (TLC), gas chromatography - mass spectrum (GC-MS) and Fourier Transform Infrared (FTIR) the major compound, betulin was structurally identified.

Conclusions: The isolated marine Paecilomyces WE3-F, therefore, showed the ability to produce a betulin yield after optimal operating conditions for antibacterial potential.
\end{abstract}

\section{INTRODUCTION}

Betulin is a pentacyclic triterpenoid, manly found at the bark of several birch species (Alakurtti et al., 2006). The presence of reactive functional groups in betulin makes it an available and convenient starting material for synthesizing new biologically active compounds (Santos et al. 2009). In fact, the antibiotics era began in 1929 with the penicillin discovery by Fleming, who considered filamentous fungi as an important source of new drugs for therapeutic use (Yu and Keller 2005). Nowadays, this micromycetes by-product inspired scientists to re-explore new metabolites for biofactories, which synthesize desired pharmatheutical products for a healthy life. The production of terpenoids by endophytic fungi (65 sesquiterpenes, 45 diterpenes, 5 meroterpenes and 12 other terpenes) and their

\footnotetext{
* Corresponding Author

Khouloud Barakat, Marine Microbiology Lab, Marine Environment Dept., National Institute of Oceanography and Fisheries, Alexandria, Egypt. Email: kh2m2[at]yahoo.com
}

biological activities were reported by Jorgeane de Souza et al., (2011). Among these filamentous fungi, the ascomycete Paecilomyces species deserve special attention according to its reputation as a source of secondary metabolites without mycotoxins production (Mioso et al. 2015). P. variotii is found worldwide; it is commonly found in air, soil, and plant litter and was frequently recovered from aquatic environments where it probably resides as dormant conidia or ascospores (Marante et al., 2012; Silva et al., 2013).

Four new polyketides were isolated from marine Paecilomyces variotii. These compounds showed inhibitory activity against pathogenic bacteria, including methicillin-resistant Staphylococcus aureus 3089 and multi-drug-resistant Vibrio parahemolyticus 7001 (Liu et al., 2011).

In the continuous search for additional bioactive metabolites, a naturally occurring anacardic acid analogue was isolated from the same fungal strain showing cytotoxicity against human and antimicrobial activity against marine pathogens Escherichia coli DC2 and Streptococcus iniae FP5228 (Liu et al., 2012). 
Hyung et al., (2013) suggested that the viriditoxin (10) extract from marine $P$. variotii is effective for preventing and treating infections caused by fish pathogenic microorganisms, particularly Aeromonas hydrophila, A. sobria, Edwardsiella tarda, Clostridium botulinum, Mycobacterium marinum, Streptococcus iniae, Vibrio parahaemolyticus, V. cholerae, V. vulnificus and V. ichthyoenteri. These extracts that have been attributed to naturally occurring antibiotic in aquaculture could improve the safety of fish consumption, since it generates a lower environmental impact because of its low toxicity and rapid degradation (Mioso et al., 2014).

In the present study, the Placket Burmen experimental design was used to optimize the submerged culture conditions for the simultaneous production of bioactive betulin by Paecilomyces WE3-F. Meanwhile, the chemical characterization of betulin was carried out using TLC, GC-MS and FTIR.

\section{MATERIALS AND METHODS}

\section{Fungal Isolation}

Marine fungi were originally isolated form Shalateen coast, Red Sea, Egypt. Briefly, sediment sample was collected in sterile plastic bags (APHA, 1998). The isolation process was carried out using the pour plate technique. One gm sediment in $30 \mathrm{ml}$ sterile sea water were applied on glucose peptone agar (GPA) and then incubated at $30^{\circ} \mathrm{C}$ for 7 days at $\mathrm{pH} 7$. Slants containing pure cultures were stored at $4{ }^{\circ} \mathrm{C}$ until further use. The macroscopic examination of fungal hyphea was then observed.

\section{Bacterial Pathogens}

Four Gram-negative bacteria: Aeromonas hydrophila, Pseudomonas aeruginosa,, Flavobacterium sp., Vibrio cholera and four Gram-positive bacteria: Bacillus cereus, Lesteria monocytogenes; Staphylococcus aureus Micrococcus luteus were kindly provided by the Microbiology Lab, Marine Environment Department, National institute of oceanography and fishers, Egypt. Stock bacterial cultures were maintained on nutrient agar slants at $4{ }^{\circ} \mathrm{C}$ with monthly transfer.

\section{Antibacterial Potential}

Screening for the antibacterial potential was carried using the disk-diffusion assay method according to Kirby-Bauer (Bauer et al., 1966) to test the inhibition of marine fungi against the tested pathogens. GPA medium was used to support the secondary metabolite production. One $\mathrm{ml}$ of pre-cultured tested bacteria $\left(\mathrm{OD}_{550}=1.0\right)$ was mixed well using $25 \mathrm{ml}$ of sterile and molten Muller-Hinton agar. Sterile discs of $6 \mathrm{~mm}$ diameter were immersed in the culture supernatant and placed on the seeded Muller-Hinton agar plates. All plates were incubated at $30 \mathrm{oC}$ for 24-48h. The inhibition zone diameters were recorded.

\section{Identification of the Potent Isolate}

Phylogenetical identification of the potent isolate was carried out using the manufacturer protocol of FavorPrep Fungi/
Yeast Genomic DNA Extraction Mini Kit (FAFYG 000). Gel documentation system (Geldoc-it, UVP, and England) was applied for data analysis using the Total lab analysis software, ww.totallab.com, (Ver.1.0.1). NCBI (http://www.ncbi.nlm.nih.gov/) software analysis was used for sequence alignment. Phylogenetic tree was constructed via ClustalW (http://www.ebi.ac.uk/Tools/msa/clustalw2/) software analysis. Isolated fungus was initially grown for 7 days on GPA medium in Petri dish.

A disc $(5 \mathrm{~mm})$ was cut from the margins of old culture of the agar plate culture and then transferred into the seed medium. The seed culture was grown in a $250 \mathrm{ml}$ flask containing $100 \mathrm{ml}$ GPA medium at $30^{\circ} \mathrm{C}$ on a rotary shaker incubator at $120 \mathrm{rev} / \mathrm{min}$ for 7 days for further studies.

\section{Effective Culture Media}

Four culture media namely; potato dextrose, glucose peptone, czapek-dox and yeast-glucose liquid media, have been used to trace the antibacterial activity response. After adjusting $\mathrm{pH}$ to 7 , the culture media were sterilized. Each medium was inoculated with $1 \mathrm{ml}(1 \times 107$ spores $/ \mathrm{ml})$ then incubated at $30 \mathrm{oC}$ under shaking condition for 7 days.

\section{Plackett-Burman Experimental Design}

The effect of medium components on the bioactive compounds produced by marine fungus was studied by applying the Plackett Burman Experimental Design (Plackett and Burman, 1946; Greasham and Inamine, 1986). In this experiment, seven factors (medium components and culturing conditions) were determined in eight combinations organized according to the Plackett Burman matrix shown in Table 1. For each variable, a high level (+1) and a low level (-1) were tested (Rajendran et al., 2007). The factors tested were: $\mathrm{Sucrose}, \mathrm{NaNO}_{3}$ and yeast extract concentrations. Also, the $\mathrm{pH}$, temperature inoculum size and incubation period of the tested fungus were also tested. The assays were performed in duplicate.

Table 1: Plackett-Burman design for seven variables.

\begin{tabular}{cccccccc}
\hline Trials & \multicolumn{7}{c}{ Independent variables } \\
\cline { 2 - 8 }$(\mathbf{n})$ & $\mathbf{1}$ & $\mathbf{2}$ & $\mathbf{3}$ & $\mathbf{4}$ & $\mathbf{5}$ & $\mathbf{6}$ & $\mathbf{7}$ \\
\hline $\mathbf{1}$ & + & + & + & - & + & - & - \\
$\mathbf{2}$ & + & + & - & + & - & - & + \\
$\mathbf{3}$ & + & - & + & - & - & + & + \\
$\mathbf{4}$ & - & + & - & - & + & + & + \\
$\mathbf{5}$ & + & - & - & + & + & + & - \\
$\mathbf{6}$ & - & - & + & + & + & - & + \\
$\mathbf{7}$ & - & + & + & + & - & + & - \\
$\mathbf{8}$ & - & - & - & - & - & - & - \\
\hline
\end{tabular}

The main effect of each factor was determined using this equation: $\operatorname{Exi}=(\Sigma \mathrm{Mi}+-\Sigma \mathrm{Mi}-) / \mathrm{N})$

Where Exi is the variable main effect; $\mathrm{Mi}+$ and $\mathrm{Mi}-$ are the calculated results of the bioactivities (inhibition zone in $\mathrm{mm}$ ). They are recorded by trial which contains positive and negative levels of independent variables (xi), respectively. $\mathrm{N}$ is the number of trials divided by 2 . A main effect figure with a positive sign 
indicates that the positive level of this variable is nearer to optimum bio activity; while a negative sign indicates that the negative level of this variable is closer to optimum bioactivity. Using Microsoft Excel, statistical t-values for equal unpaired samples were calculated for the determination of variable significance (Al-Sarrani and El-Naggar, 2006).

\section{Extraction of the Active Compound(S)}

Four solvent systems namely: chloroform, dichloromethane, diethyl ether and ethyl acetate were individually applied for the extraction purpose. The organic layer was separated and concentrated under vacuum using rotary evaporator (STUART, RE300DB) to obtain the oily crude substance. Ten liters of culture filtrate of marine fungus were extracted from the supernatant using 1:1 (v/v) supernatant: dichlormethane. The overall crude extract amounted to $834 \mathrm{mg}$. The crude extract was then tested using the disc diffusion assay method.

\section{ANALYTICAL METHODS}

\section{Thin layer chromatography}

The selected dichloromethane crude extract was fractionated using the silica gel thin layer chromatography sheet (60GF254 Merck). Then, the crude was applied as a spot and left to complete separation. The plates stood for solvent evaporation and the $\mathrm{R}_{f}$ of the result spot was recorded. The collected samples were evaporated, weighed and dissolved in dichlormethane to be applied on pathogens inoculated plates. The bioactivity of the collected samples was checked for the eight pathogens using the disc diffusion assay.

\section{Gas Chromatography-Mass Spectrum analysis}

Oily crude was dissolved in $10 \mathrm{ml}$ of dichlormethane and subjected to chromatographic analysis. The active dichlormethane fraction that was subjected to Gas chromatograph-mass spectrometer coupling (GC/MS) measurements were performed on an Agilent Technologies 7890A GC System with a flame ionization detector, a 5975C inert XL MSD Triple-Axis Mass Detector and Agilent 19,091S-433 Trace Analysis column. GCconditions: $1 \mu \mathrm{L}$ of sample was injected with an evaporation temperature of $250{ }^{\circ} \mathrm{C}, 1.8 \mathrm{bar}, 2.5 \mathrm{~mL} / \mathrm{min}$, split $20: 1$. He, the carrier gas temperature was gradient $50{ }^{\circ} \mathrm{C} / 1 \mathrm{~min}, 40{ }^{\circ} \mathrm{C} / \mathrm{min}$ gradient $300{ }^{\circ} \mathrm{C} / \mathrm{min}, 300{ }^{\circ} \mathrm{C} / 5 \mathrm{~min}$. The components were identified by comparing their retention times to those of authentic samples, as well as by comparing their mass spectra with those of Wiley 275 Library (Wiley, 2006). Quantitative data were obtained by the peak normalization technique using integrated FID response.

\section{Fourier Transform Infrared analysis}

Dichloromethane crude was subjected to FTIRspectroscope (Perkin Elmer, USA) in the mid IR region of 400$4000 \mathrm{~cm}^{-1}$ with 16 scan speed using $\mathrm{KBr}$ discs.

\section{RESULTS AND DISCUSSION}

Paecilomyces sp. isolated from a broad range of habitats drives the diversification of new high-value-added secondary metabolites that play an important role in a healthy life, leading new drug discoveries, developments of new trends, and prospects for the bioactivity potential of this ascomycete (Mioso $e t$ al., 2015)

\section{MARINE ACTIVE ISOLATE}

After 7 days of incubation, marine Paecilomyces WE3-F was selected according to its highest antibacterial activities, where, the maximum activity recorded was $25 \mathrm{~mm}$ against $V$. cholera as Gram positive and $27 \mathrm{~mm}$ against $S$. aureus as Gram negative; whereas, lower activity recorded for both $B$. cereus and $L$. monocytogenes at $10 \mathrm{~mm}$ (Table 2).

Table 2: Bioactivity pattern of Paecilomyces WE3-F.

Gram Negative Gram Positive

\begin{tabular}{|c|c|c|c|c|c|c|c|c|}
\hline Test organism & 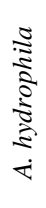 & $\begin{array}{l}\dot{2} \\
\text { के } \\
\vdots \\
5 \\
0 \\
0 \\
0 \\
\vdots \\
\vdots \\
1\end{array}$ & 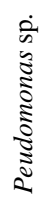 & $\frac{\frac{0}{0}}{\frac{0}{0}}$ & $\begin{array}{c}\tilde{\Xi} \\
\vdots \\
\vdots \\
u \\
0 \\
\infty\end{array}$ & 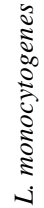 & 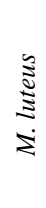 & $\begin{array}{c}3 \\
\vdots \\
\vdots \\
\vdots \\
\tilde{z} \\
\tilde{\omega}\end{array}$ \\
\hline Inhibition zone $(\mathrm{mm})$ & 23 & 15 & 23 & 25 & 10 & 10 & 20 & 27 \\
\hline
\end{tabular}

Compared with our results, cell free culture from Paecilomyces fumosoroseus obtained after 21 days of incubation exhibited highest activity for pathogenic bacteria including: Escherichia coli $(32 \mathrm{~mm})$, Bacillus subtilis $(18 \mathrm{~mm})$ and Salmonella typhi (12 mm); whereas, it was lower for Pseudomonas aeruginosa $(10 \mathrm{~mm})$, and showed no activity for Klebsiella pneumoniae (Gulwani et al., 2015). Also, different Pacelomyces sp. cultivated on PDA for 5 days, exhibited antibacterial activities against $B$. subtilis, $S$. aureus with averages of inhibition zone 27 and $29 \mathrm{~mm}$, respectively (Lee et al., 2005).

In our present study, the marine potent isolate was analyzed for its $18 \mathrm{~S}$ rRNA gene, and the phylogenetic relationship showed that this strain is very close to the strain type, Paecilomyces WE3-F (Figure 1).

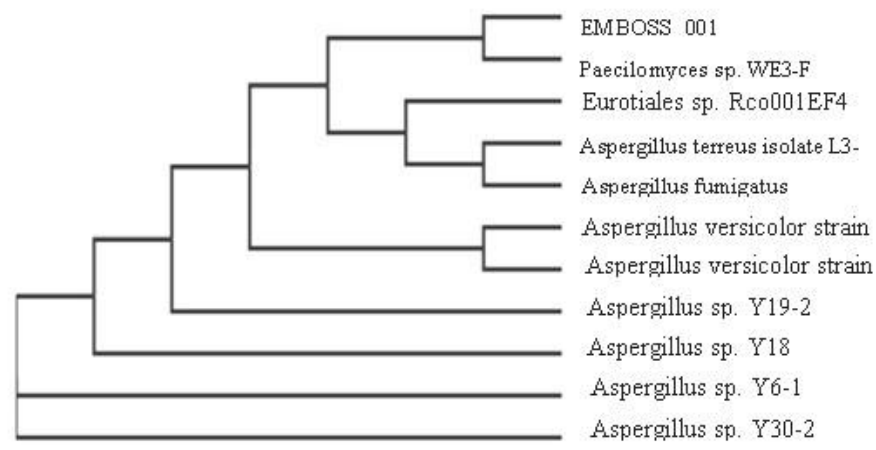

Fig. 1: Phylogenetic tree for Paecilomyces WE3-F based on specific gene sequence. 
Table 3: Bioactivity of Paecilomyces WE3-F at different culture media for Gram -ve and Gram +ve bacteria.

\begin{tabular}{|c|c|c|c|c|c|c|c|c|c|c|}
\hline \multirow[t]{3}{*}{ Media } & \multicolumn{10}{|c|}{ Inhibition zone (mm) } \\
\hline & \multicolumn{5}{|c|}{ Gram -ve bacteria } & \multicolumn{5}{|c|}{ Gram +ve bacteria } \\
\hline & $\begin{array}{c}A . \\
\text { hydrophila }\end{array}$ & $\begin{array}{c}\text { Flavobacter } \\
\text { sp. }\end{array}$ & Peudomonas sp & V. cholera & AVG & B. cereus & $\begin{array}{c}\text { L. } \\
\text { monocytogenes }\end{array}$ & $\begin{array}{c}\text { M. } \\
\text { luteus }\end{array}$ & St. aureus & AVG \\
\hline Potato Dextrose & 6 & 11 & 6 & 10 & 8.25 & 0 & 7 & 10 & 7 & 6 \\
\hline Glucose Peptone & 23 & 15 & 23 & 25 & 21.5 & 10 & 10 & 20 & 27 & 17.5 \\
\hline Czapek-dox & 25 & 15 & 25 & 27 & 23 & 15 & 12 & 25 & 25 & 19.25 \\
\hline Yeast-Glucose & 7 & 0 & 12 & 12 & 7.75 & 0 & 7 & 9 & 9 & 6.25 \\
\hline
\end{tabular}

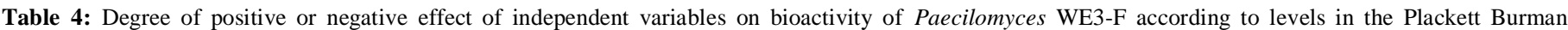
experiments.

\begin{tabular}{|c|c|c|c|c|c|c|c|c|c|c|c|c|c|c|}
\hline \multirow{4}{*}{$\begin{array}{l}\text { Trials } \\
(n=8)\end{array}$} & \multicolumn{14}{|c|}{ Variables (Factors) } \\
\hline & \multirow{2}{*}{\multicolumn{4}{|c|}{ Sucrose }} & \multirow{2}{*}{\multicolumn{6}{|c|}{$\begin{array}{cl}\text { Inhibition zone }(\mathrm{mm}) & \\
\mathrm{pH} & \text { Temperature }\left({ }^{\circ} \mathrm{C}\right)\end{array}$}} & & & & \\
\hline & & & & & & & & pH & & & \multicolumn{2}{|c|}{ Inoculum size } & \multicolumn{2}{|c|}{ Incubation period } \\
\hline & + & - & + & - & + & - & + & - & + & - & + & - & + & - \\
\hline 1 & 3.4 & & 3.4 & & 3.4 & & 3.4 & & 3.4 & & 3.4 & & 3.4 & \\
\hline 2 & 5.4 & & 5.4 & & 5.4 & & 5.4 & & & 5.4 & & 5.4 & & 5.4 \\
\hline 3 & 10.5 & & & 10.5 & & 10.5 & & 10.5 & 10.5 & & & 10.5 & & 10.5 \\
\hline 4 & 17.2 & & & 17.2 & & 17.2 & & 17.2 & & 17.2 & 17.2 & & 17.2 & \\
\hline 5 & & 19.9 & 19.9 & & 19.9 & & & 19.9 & & 19.9 & 19.9 & & & 19.9 \\
\hline 6 & & 7.8 & 7.8 & & 7.8 & & & 7.8 & 7.8 & & & 7.8 & 7.8 & \\
\hline 7 & & 4.1 & & 4.1 & & 10.5 & 4.1 & & & 4.1 & & 4.1 & 4.1 & \\
\hline 8 & & 9.8 & & 9.8 & & 17.2 & 9.8 & & 9.8 & & 9.8 & & & 9.8 \\
\hline $\mathbf{N}$ & 4 & 4 & 4 & 4 & 4 & 4 & 4 & 4 & 4 & 4 & 4 & 4 & 4 & 4 \\
\hline Mean & 9.1 & 10.4 & 9.1 & 10.4 & 9.1 & 10.4 & 5.7 & 13.9 & 7.9 & 11.6 & 12.6 & 7.0 & 8.1 & 11.4 \\
\hline Main effect & \multicolumn{2}{|c|}{-1.3} & \multicolumn{2}{|c|}{-1.2} & \multicolumn{2}{|c|}{-1.2} & \multicolumn{2}{|c|}{-8.2} & \multicolumn{2}{|c|}{-3.8} & \multicolumn{2}{|c|}{5.6} & \multicolumn{2}{|c|}{-3.3} \\
\hline t-value & \multicolumn{2}{|c|}{0.278} & \multicolumn{2}{|c|}{0.269} & \multicolumn{2}{|c|}{0.269} & \multicolumn{2}{|c|}{2.59} & \multicolumn{2}{|c|}{0.871} & \multicolumn{2}{|c|}{1.405} & \multicolumn{2}{|c|}{0.744} \\
\hline Deg. of sign. & \multicolumn{2}{|c|}{ N.S } & \multicolumn{2}{|c|}{ N.S } & \multicolumn{2}{|c|}{ N.S } & \multicolumn{2}{|c|}{$95 \%(-)$} & \multicolumn{2}{|c|}{ N.S } & \multicolumn{2}{|c|}{$80 \%(+)$} & \multicolumn{2}{|c|}{ N.S } \\
\hline
\end{tabular}

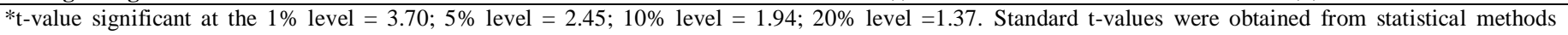
(Snedecor and Cochran, 1989).

\section{EFFECTIVE MEDIA FOR BIOACTIVITY}

Averages of inhibition zone of Paecilomyces WE3-F using four culture media was represented in Table 3 a \& b. Using Czapek-dox medium, containing yeast and sucrose as main $\mathrm{N}$ and $\mathrm{C}$ sources, the highest activities were recorded at $23 \mathrm{~mm}$ and 19.24 $\mathrm{mm}$ against $\mathrm{G}$-ve and $\mathrm{G}+\mathrm{ve}$, respectively; whereas, lower activities were represented using potato dextrose and yeast glucose medium. Two different liquid culture using $P$. fumosoroseus were tested for biocontrol efficacy using basal salts medium (Sandoval-Coronado et al., 2001). Another ten different culture media were used to investigate a mycelia growth of $P$. fumosoroseus, where, only two media were the favorable carbon and nitrogen source for maximal growth (Shim et al., 2003). Recently, the growth of $P$. hepiali in various agar media was studied, where, the addition of peptone improved mycelial growth and the most favorable carbon sources were mannose, fructose and glucose (Chioza, and Ohga, 2013).

Our study revealed that Czapek-dox medium containing in $\mathrm{g} / \mathrm{l}$ : sucrose $20 ; \mathrm{NaNO}_{3} 2$; yeast 2, were further used within an experimental design to elucidate the maximum activity of Paecilomyces WE3-F.

\section{ELUCIDATION OF MEDIUM COMPONENTS FOR THE BIOACTIVITY}

Optimization of the components of the selected Czapekdox broth medium for the maximum activity using Paecilomyces
WE3-F was determined. The nutrient medium factors and cultivation conditions were screened by applying the PlackettBurmann design as described in the materials and methods section. Table 4 shows that trial 5 yielded the highest activity of Paecilomyces WE3-F at $19.9 \mathrm{~mm}$ which was obtained by incubating $1.5 \mathrm{ml}\left(2.3 \times 10^{7}\right.$ spores $\left./ \mathrm{ml}\right)$ of the fungus for 5 days in $100 \mathrm{ml}$ medium containing in $\mathrm{g} / \mathrm{l}$ : sucrose $10, \mathrm{NaNO}_{3} 2.5$ and yeast extract 3, at incubation temperature of $25^{\circ} \mathrm{C}$ and $\mathrm{pH}$. These results revealed that the degree of significance of $\mathrm{pH}$ and inoculum size was at 95 and $80 \%$, respectively. It also showed that the decrease of $\mathrm{pH}$ and the increase of inoculum size caused an increase in activities using marine Paecilomyces WE3-F (at the 5 and $20 \%$ level of significance) (Figure 2). Using response surface methodology to optimize the extract process of mycelial polysaccharides from $P$. hepiali, as well, test antioxidant activities were studied by Yu et al (2011).

In addition, the best growth for $P$. hepiali in an optimized media was obtained at $25^{\circ} \mathrm{C}$ in 14 days with initial $\mathrm{pH}$ range from 6 to 8 (Chioza, and Ohga, 2013). Giraldo et al. (2012) observed that $P$.variotii is able to produce extracellular invertases when grown for $96 \mathrm{~h}$, where, the optimal temperature and $\mathrm{pH}$ values were $60^{\circ} \mathrm{C}$ and $4 \cdot 0-4 \cdot 5$, respectively. Statistical method involves changing one independent variable was carried out for medium optimization condition for Inonotus obliquus yield of betulin, where, optimal $\mathrm{pH}$ was at 6.0 and optimum temperature was at $25^{\circ} \mathrm{C}$ (Bai et al., 2012). 


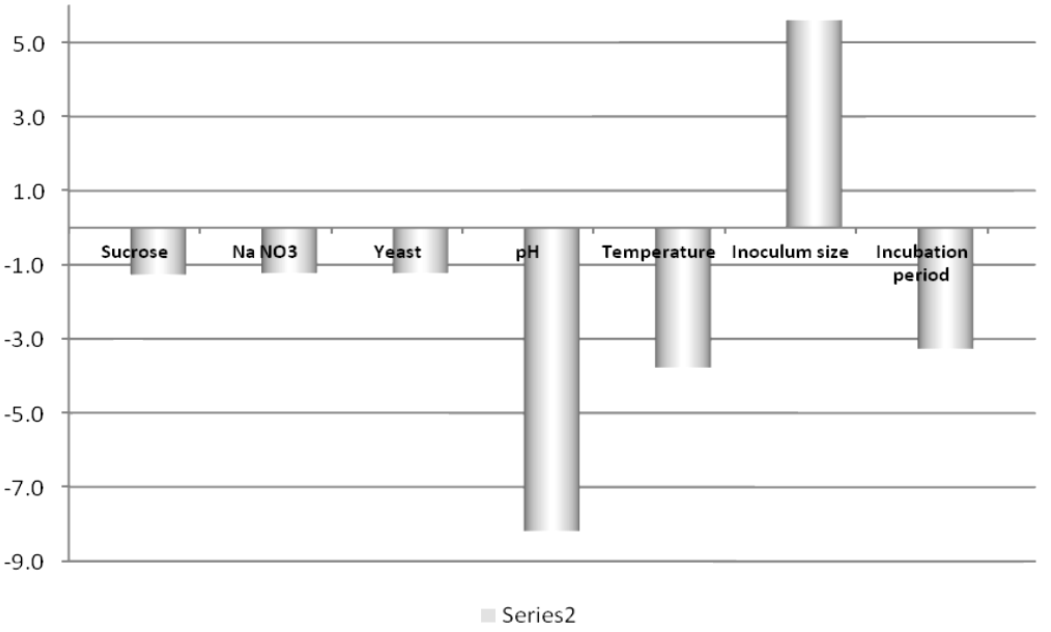

Fig. 2: Bioactivity main effect of the medium constituents after applying Plackett-Burman experimental design.
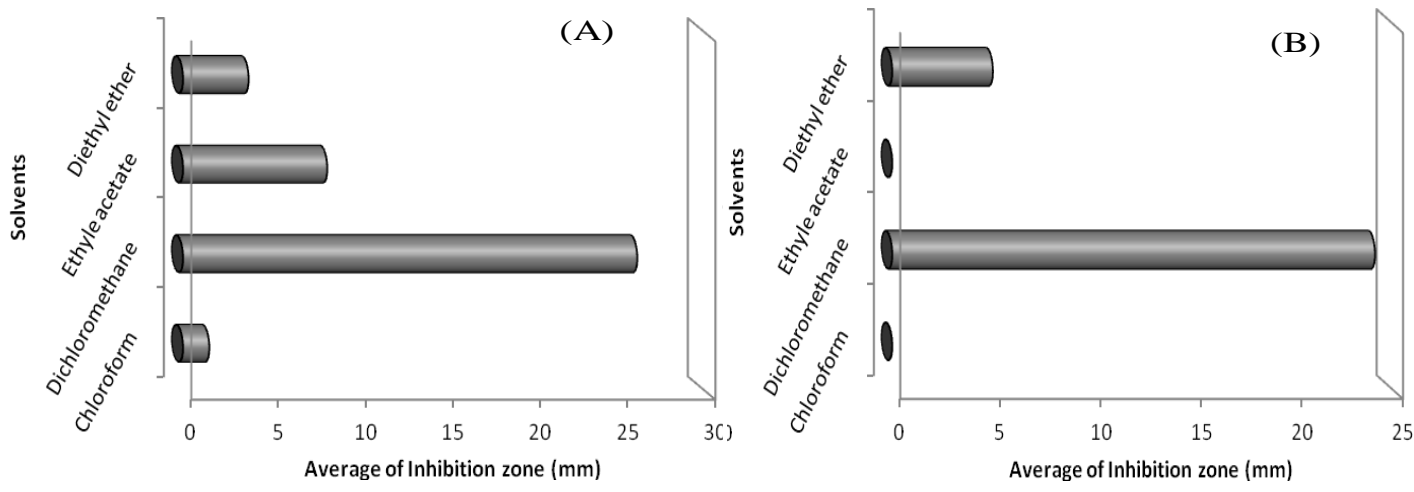

Fig. 3: Bioactivity of Paecilomyces WE3-F extracts against the Gram +ve (A) and Gram -ve bacteria using different solvents.
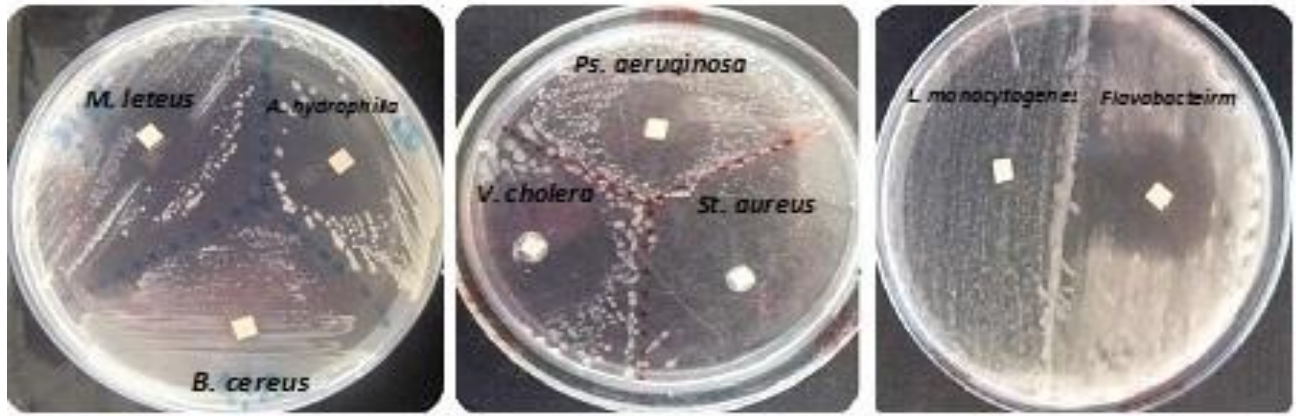

Fig. 4: Antibacterial activity of dichloromethane extract against Gram-positive and Gram-negative tested bacteria using disc-diffusion method.

\section{DETERMINATION OF THE APPROPRIATE SOLVENT(S) FOR EXTRACTION OF THE ACTIVE AGENT}

The results showed that dichloromethane solvent was selected for the extraction procedures where the yielded extract obtaining showed the highest average zone of inhibition; 26 and 24 $\mathrm{mm}$ against Gram -ve and +ve, respectively (Figure 3). However, the other solvent showed low or no antimicrobial activity against the eight pathogens (Figure 4). Compared with our results, the extracts from $P$. lilacinus were evaluated for antimicrobial activity by disc diffusion method showed activity for Gram-positive
S. aureus and L. monocytogenes at average inhibition zone 20.76 $\mathrm{mm}$, even while, Gram-negative bacteria were not affected by the tested compounds (Teles et al., 2013a). The antimicrobial activity of the methanol crude extract from marine-derived Paecilomyces sp. was determined for MRSA, Escherichia coli, A. hydrophila and $C$. albicans at 18, 6, 9 and $7 \mathrm{~mm}$, respectively (Liu et al., 2011). Ethyl acetate extract of $P$. variotii FEL24 presented antimicrobial activities ranged from 19 to $35 \mathrm{~mm}$ (Silva et al, 2011). The active ethyl acetate extract of $P$. lilacinus showed antibacterial activity for some pathogenic bacteria by agar diffusion assay: 19, 19.3 and $16 \mathrm{~mm}$ against Ps. syringae, $R$. 
solanacearum and E. coli; whereas, there was no activity against $X$. vesicatoria, B. cereus B. subtilis and S. aureus (Srivastava and Anandrao, 2015).

\section{PHYSICOCHEMICAL CHARACTERIZATION OF THE CRUDE EXTRACT}

Paecilomyces genus includes many species capable to produce secondary metabolites which belongs to different chemical groups with wide biological activity such as paecilosetin (Lang et al., 2005), paecilaminol (Ui et al., 2006), paecilodepsipeptide A (Isaka et al., 2007), paecilin A and B (Guo et al., 2007). Using silica gel TLC plate, dichloromethane crude extract was run as concentrated spots $\left(\mathrm{R}_{f}=0.90\right)$ then scratched to estimate its bioactivity for the eight tested pathogens by disc diffusion assay. The extracts from $P$. lilacinusto assayed were prepared by dissolution on a suitable solvent and applied in readymade TLC plates that developed a yellow color in the plates (Teles and Takahashi, 2013b). The extract of $P$. variotii FEL32 strain submitted to TLC yielded two spots of $\mathrm{R}_{f} 0.48$ and 0.70 (Silva et al, 2011). Spectroscopic analysis of the separated spot
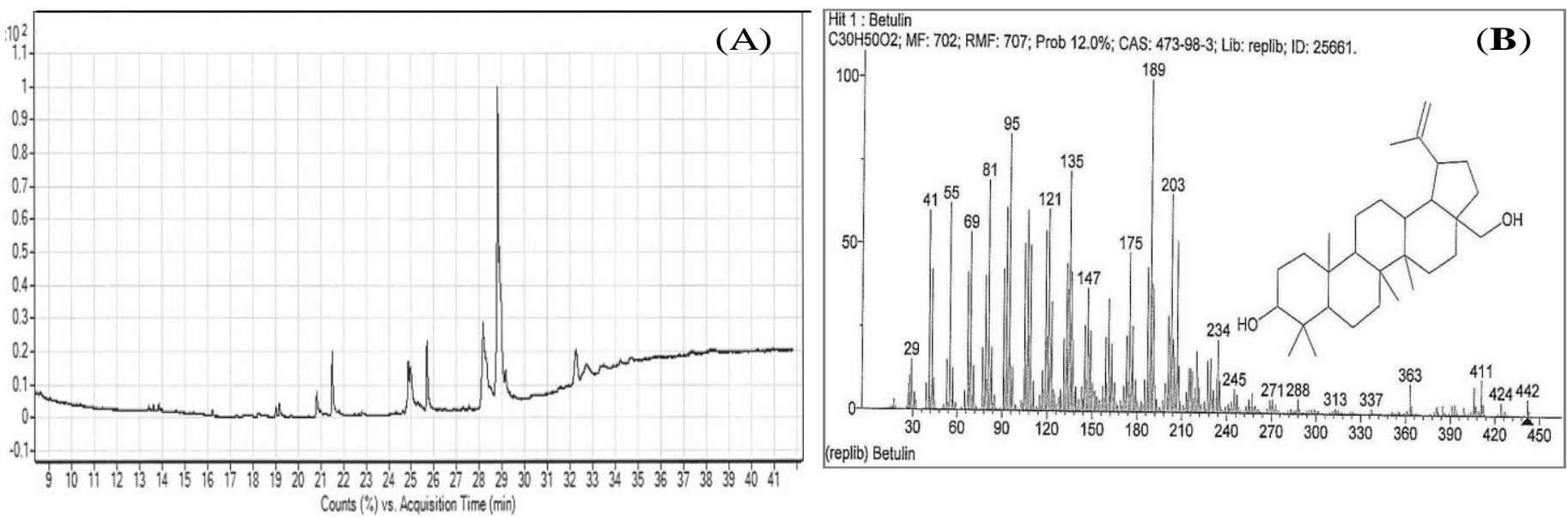

Fig. 5: Gas Chromatography-Mass Spectra showing the major peak in GC analysis (A) and identified compound "betulin" in Mass Spectral analysis (B).

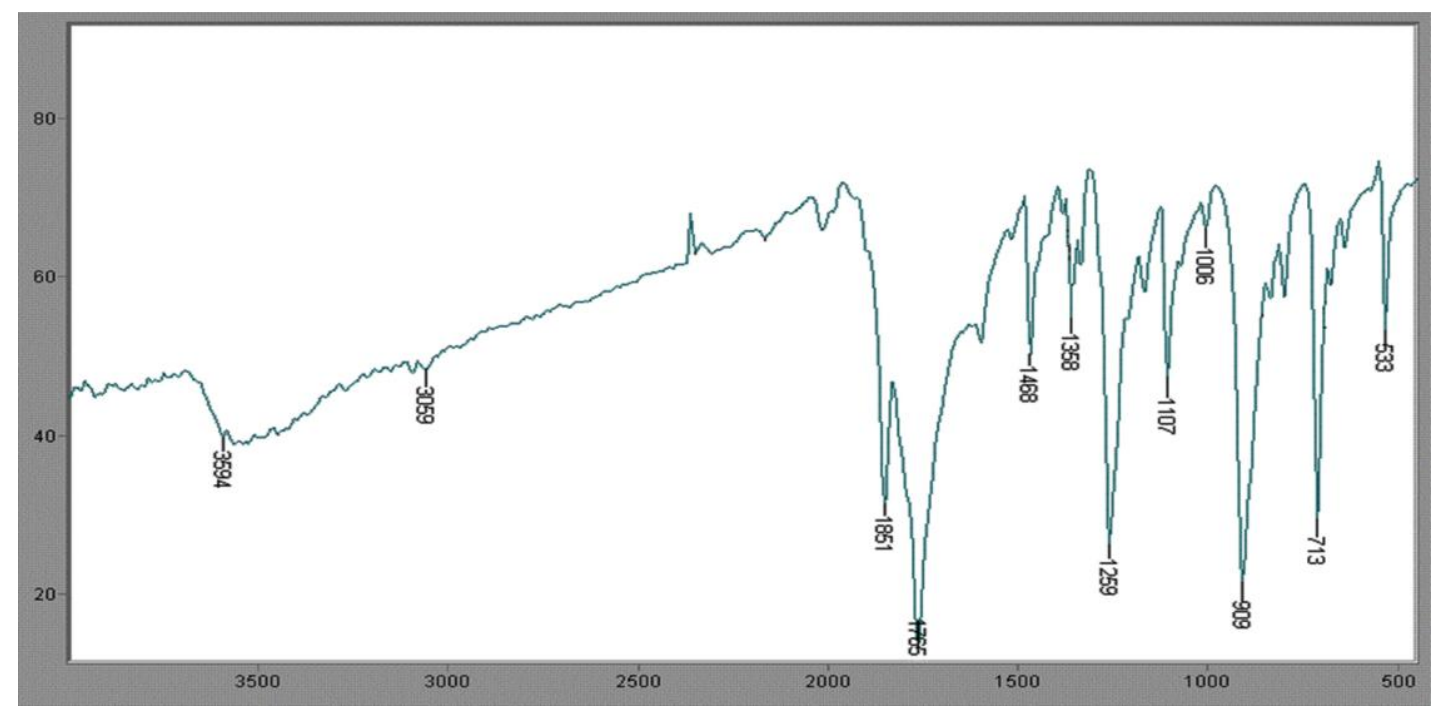

Fig. 6: FT-IR trace of betulin as a maior product. 
The FT-IR spectrum of bioactive exopolysaccharide from a native Paecilomyces sp. showed characteristic bands at different wave lengths (Naturforsch, 2011). In conclusion, work reports the isolation of a marine Paecilomyces WE3-F showing the ability to produce betulin with antibacterial potential.

Using Plackette Burman experimental design, it was possible to determine optimal operating conditions to obtain a high betulin yield. This metabolite could be used in further investigation as a potential candidate for analytical purposes and /or further biotechnological applications.

\section{REFERENCES}

Alakurtti S, Makela T, Koskimies S, Yli-Kauhaluoma J. Pharmacological properties of the ubiquitous natural product betulin. Eur $\mathbf{J}$ Pharm Sci, 2006; 29:1-13.

Al-Sarrani A, El-Naggar M. Application of Plackett-Burman factorial design to improve citrinin production in Monascus ruber batch cultures. Bot Stud, 2006; 47:167-174.

APHA (American Public Health Association). 1998. American Water Works Association, and Water Pollution Control Federation, Standard methods for the analysis of water and wastewater (20th ed.): Washington, D.C., American Public Health Association.

Bai Y-H, Feng Y-Q, Mao D-B, Xu Ch-P. Optimization for betulin production from mycelial culture of Inonotus obliquus by orthogonal design and evaluation of its antioxidant activity. J Taiwan Inst Chem Engineers, 2012; 43: 663-669.

Bauer AW, Kirby WM, Sherris JC, Turck M. Antibiotic susceptibility testing by a standardized single disk method. Am J Clin Pathol, 1966; 45: 493-496.

Chioza A, Ohga S. Mycelial Growth of Paecilomyces hepiali in Various Agar Media and Yield of Fruit Bodies in Rice Based Media. Advances Microbiol, 2013; 3: 529-536.

Giraldo MA, Silva TM, Salvato F, Terenzi HF, Jorge JA, Guimarães LHS. Thermostable invertases from Paecylomyces variotii produced under submerged and solid-state fermentation using agroindustrial residues. World J Microbiol Biotechnol, 2012; 28: 463-472.

Greasham R, Inamine E. 1986. Nutritional improvement of processes. In: Manual of Industrial Microbiology and Biotechnology. Demain AL \& Solomon NA (eds). American Soc Microbiol, Washington D.C. 41-48.

Gulwani N, Shukla H, Sandhu SS. Screening the Antibacterial Potential of Paecilomyces fumosoroseus against Some Pathogenic Bacteria. American J Adv Drug Delivery, 2015; 3(1): 24-31.

Guo Z, She Z, Shao C, Wen L, Liu F, Zheng Z, Lin Y. 1H and 13C NMR signal assignments of paecilin $\mathrm{A}$ and $\mathrm{B}$, two new chromone derivatives from mangrove endophytic fungus Paecilomyces sp. (tree 1-7). Magnetic Resonance Chem, 2007; 45:777-780.

Hyung JJ, Kang H, Joong JJ, Soo KY. 2013. Paecilomyces variotii extracts for preventing and treating infections caused by fish pathogenic microorganisms. KR Patent, 2013051523.

Isaka M, Palasan S, Lapanun S, Sriklung K. Paecilodepsipeptide A, an antimalarial and antitumor cyclohexadepsipeptideo from the insect pathogenic fungus Paecilomyces cinnamomeus BCC9616. J Nat Prod, 2007; 70:675-678.

Jorgeane de Souza J, Vieira IJC, Rodrigues-Filho E, Braz-Filho R. Terpenoids from Endophytic Fungi. Molecules, 2011; 16(12):10604-18.

Lang G, Blunt JW, Cummings NJ, Cole ALJ, Munro MHG. Paecilosetin, a new bioactive fungal metabolite from a New Zealand isolate of Paecilomyces farinosus. J Nat Prod, 2005; 68:810-811.

Lee S-Y, Nakajima I, Ihara F, Kinoshita H, Nihira T, Cultivation of entomopathogenic fungi for the search of antibacterial compounds. Mycopathologia, 2005; 160: 321-325.

Liu J, Li F, Kim EL, Li JL, Hong J, Bae KS, Chung HY, Kim HS, Jung JH. Antibacterial Polyketides from the Jellyfish-Derived Fungus Paecilomyces variotii. J Nat Prod, 2011; 74: 1826-1829.

Liu J, Li F, Lee Y-M, Li JL, Hong J-K, Yoon W-D, Kim E-K, Jung $\mathrm{J}-\mathrm{H}$. An anacardic acid analog from the jellyfish-derived fungus Paecilomyces variotii. J Nat Prod, 2012; 18: 8-12.

Marante TFJ, Mioso R, Barrera BJ, González GJE, Rodríguez SJJ, Bravo H., de Laguna I. Structural characterization and metabolite profiling of the facultative marine fungus Paecilomyces variotii. Ann Microbiol, 2012; 62: 1601-1607.

Mioso R, Marante FJT, Bravo de Laguna IH, Bessonart M. Química de productos naturales y acuicultura: un enfoque interdisciplinar. Química Nova, 2014; 37: 513-520.

Mioso R, Marante FJT, Bravo de Laguna IH. The Chemical Diversity of the Ascomycete Fungus Paecilomyces variotii. Appl Biochem Biotechnol, 2015; 177(4): 781-791.

Naturforsch ZC. Antibacterial activity of an oligosaccharide of native Paecilomyces sp. and its aminoglycosylated derivative. 2011; 66(3-4): 123-128.

Plackett RL, Burman JP. The design of optimum multifactorial experiments. Biometrika, 1946; 33:305-325.

Rajendran A, Sundaramurthy AB, Thangavelu V. Statistical evaluation of medium components using Plackett-Burman experimental design and kinetic modeling of lipase production by Bacillus sphaericus. Chem Biochem Eng, 2007; 21:181-188.

Sandoval-Coronado CF, Luna-Olvera HA, Arévalo-Niño K, Jackson MA, Poprawski TJ, Galán-Wong LJ. Drying and formulation of blastospores of Paecilomyces fumosoroseus (Hyphomycetes) produced in two different liquid media. World J Microbiol Biotechnol, 2001; 17(4): 423-428.

Santos RC, Salvador JAR, Marín S, Cascante M. Novel semisynthetic derivatives of betulin and betulinic acid with cytotoxic activity. Bioorg Med Chem, 2009; 17(17): 6241-6250.

Shim SM, Lee KR, Kim SH, Im KH, Kim JW, Lee UY, Shim JO, Lee MW, Lee TS. The Optimal Culture Conditions Affecting the Mycelial Growth and Fruiting Body Formation of Paecilomyces fumosoroseus. Mycobiol, 2003; 31(4): 214-220.

Silva MRO, Almeida AC, Arruda FVF, Gusmão N. 2011. Endophytic fungi from brazilian mangrove plant Laguncularia racemosa (L.) Gaertn. (Combretaceae): their antimicrobial potential Science against microbial pathogens: communicating current research and technological advances A. Méndez-Vilas (Ed.) 1260-1266.

Silva MRO, Kawai K, Hosoe T, Takaki CGM, Gusmão BN, Fukushima K. 2013. Viriditoxin, an antibacterial substance produced by mangrove endophytic fungus Paecilomyces variotii. In A. Méndez-Vilas (Ed.), Microbial pathogens and strategies for combating them: science, technology and education, 1406-1411. Badajoz: Formatex Res. Pub.

Snedecor GW, Cochran WG. Statistical Methods. 1989. Eighth Edition, Iowa State University Press.

Srivastava A, Anandrao RK. Antimicrobial Potential of Fungal Endophytes Isolated From Leaves of Prosopis Juliflora (Sw.) Dc., An Important Weed. Inter J Pharm Pharm Sc, 2015; 7(12): 128-136.

Teles APC, Atalibab GS, Takahashib JA. Modulation of Paecilomyces lilacinus antimicrobial metabolite production by co-culturing with Salmonella typhimurium. Nat Prod Res, 2013a; 27(17): 1598-1601.

Teles APC, Takahash JA. Paecilomide, a new acetylcholinesterase inhibitor from Paecilomyces lilacinus. Microbiolog Res, 2013b; 168(4): 204210 .

Ui H, Shiomi K, Suzuki H, Hatano H, Morimoto H, Yamaguchi Y, Masuma R, Sakamoto K, Kita K, Miyoshi H, Tomoda H, Tanaka H, Omura S. Paecilaminol, a new NADH-fumarate reductase inhibitor produced by Paecilomyces sp. FKI-0550. J Antibiotics, 2006; 59:591-596.

Wang H, Hong J, Yin J, Moon HR, Liu Y, Wei X, Oh DC, Jung JH. Dimeric Octaketide Spiroketals from the Jellyfish-Derived Fungus Paecilomyces variotii J08NF-1. , 2015; 78(11): 2832-2836.

Wiley J. Wiley Registry of Mass Spectral Data, eighth Edition "software". 2006; Wiley's Scientific, Technical, and Medical Databases.

$\mathrm{Yu} \mathrm{J-H}$ and Keller N. Regulation of Secondary Metabolism in Filamentous Fungi. Ann Rev Phytopath, 2005; 43: 437-458.

Yu SJ, Zhang Y, Li CR, Zhang Q, Ma ZY, Fan MZ. Optimization of ultrasonic extraction of mycelial polysaccharides from Paecilomyces hepiali using response surface methodology and its antioxidant activity. African J Biotechnol, 2011; 10(75): 17241-17250.

\section{How to cite this article:}

Barakat K, Saleh M. Bioactive Betulin produced by marine Paecilomyces WE3-F. J App Pharm Sci, 2016; 6 (03): 034-040. 